\title{
ENGENHARIA E MOVIMENTO ESTUDANTIL: INTERFACES DA FORMAÇÃO PROFISSIONAL
}

DOI: 10.37702/2175-957X.COBENGE.2021.3501

Marcos Johari Provezani Silva - joharipro@gmail.com

Universidade de Taubaté

RUA JOSEPHINA GONÇALVES DE ABREU, 106106

35681-045 - Itaúna - MG

Eliene Oliveira Lucas - eliene.lucas@ufv.br

Universidade Federal de Viçosa

Rua padre anchieta 90

36570-242 - Viçosa - MG

Resumo: O Movimento Estudantil tem papel relevante nos debates sobre a educação no país, sendo o caminho tomado pelos estudantes na organização e apresentação de demandas e propostas para a melhoria da educação. Diversos estudos revelam que a participação no movimento estudantil contribui para a formação social e cidadã, mas é preciso compreender como ocorre a interface entre essa participação e a formação profissional. O objetivo deste estudo é compreender essa interface e aprofundar o conhecimento sobre a participação em atividades complementares e a formação profissional. Este estudo parte da hipótese "A participação no movimento estudantil contribui para a formação profissional em Engenharia". Foi realizada uma revisão de literatura para se compreender os pontos relevantes para a formação profissional em engenharia, quais desafios existentes e as características das organizações estudantis. Em seguida foi realizada uma análise e discussão dos dados na qual se confirmou a hipótese inicial, uma vez que a participação no movimento estudantil desenvolve diversas soft skills e hard skills que são previstas na formação educacional e desejáveis na atuação profissional.

Palavras-chave: Formação Profissional; Movimento Estudantil; Educação em Engenharia; Habilidades 


\section{ENGENHARIA E MOVIMENTO ESTUDANTIL: INTERFACES DA FORMAÇÃO PROFISSIONAL}

\section{INTRODUÇÃO}

As Diretrizes Curriculares Nacionais (DCNs) para Engenharia (BRASIL, 2019) definem a formação profissional de engenheiros e engenheiras. Institui o perfil e competências esperadas para os egressos, e como deve ser feita a organização, o desenvolvimento e avaliação dos cursos. Em seu décimo artigo apresenta que "as atividades complementares (...) devem contribuir efetivamente para o desenvolvimento das competências previstas para o egresso".

Por sua vez, o Fórum Econômico Mundial tem identificado diversas alterações relacionadas ao futuro do trabalho, divulgando textos detalhados como o relatório "O Futuro do Trabalho" (WEF, 2020). Percebe-se também que a questão do trabalho é central para a definição da identidade de estudantes jovens ou adultos (GROPPO, 2016). Assim, é importante entender como as organizações estudantis contribuem para sua formação, visto ser um ponto relevante da identidade.

O Movimento Estudantil possui um sentido mais estrito e um mais amplo. Mais estritamente se refere à participação em entidades como Centros e Diretórios Acadêmicos ou no Diretório Central dos Estudantes, além de coletivos organizados regionalmente ou nacionalmente. Em um sentido mais amplo, o Movimento Estudantil com organização estudantil engloba outras organizações como Empresas Júniores, grupos religiosos e grupos ambientais.

Este estudo tem como objetivo aprofundar o conhecimento sobre os impactos de atividades complementares na formação profissional do estudante de engenharia. Especificamente, busca-se compreender a interface entre a formação profissional e a participação em organizações e entidades do Movimento Estudantil. Para compreender se a participação no Movimento Estudantil auxilia na formação profissional e pessoal dos estudantes, contribuindo para suas atividades quando egresso, foi proposta a seguinte a hipótese "A participação no Movimento Estudantil contribui para a formação profissional em engenharia".

Foram identificados os pontos relevantes para a formação profissional em engenharia, utilizando o relatório "O Futuro do Emprego" do Fórum Econômico Mundial e as Diretrizes Curriculares Nacionais (DCNs) para o curso de Engenharia. Em seguida foi realizada uma pesquisa bibliográfica sobre os temas Formação Profissional em Engenharia e Movimento Estudantil, para se compreender as suas características. Por fim foram analisadas as convergências entre a formação profissional do engenheiro desejada e a relação com a participação no Movimento Estudantil.

\section{REFERENCIAL TEÓRICO}

\subsection{Relatório "O Futuro do Trabalho"}

Em outubro de 2020 foi apresentado pelo Fórum Econômico Mundial um relatório apresenta uma análise sobre o futuro do trabalho e as mudanças já percebidas. O relatório considera os impactos provocados pela pandemia de COVID19, impactos de mecanização e automação, as mudanças provocadas por novas tecnologias entre outros fatores. É apresentado que está em curso uma mudança na forma de se organizar o trabalho e a 
divisão de atividades entre humanos, máquinas e algoritmos e a reorganização provocará a extinção de algumas categorias de empregos e a criação de outras (WEF, 2020).

O relatório identifica alterações referentes aos campos da engenharia. Dentre as vinte funções com maiores crescimento de demanda figuram funções relacionadas diretamente ou indiretamente à engenharia como especialistas nas seguintes áreas de estudo: automação de processos, engenharia robótica, gestão de projetos, engenharia de fontes renováveis e "Engenharia para Fintechs" (no original FinTech Engineers). Percebese também uma transição de carreira de engenheiros/as para áreas emergentes (WEF, 2020).

O texto do Fórum Econômico Mundial também especifica as habilidades mais demandadas pelas organização no cenário brasileiro. Os resultados são ordenados por frequência de citação na pesquisa e são apresentados no Quadro 01:

Quadro 01: Habilidades demandadas profissionais no Brasil

\begin{tabular}{c|c}
\hline Pos. & Habilidades Emergente \\
\hline 1 & Aprendizado ativo e estratégias de aprendizagem \\
\hline 2 & Pensamento analítico e inovador \\
\hline 3 & Criatividade, Originalidade e Inovação \\
\hline 4 & Liderança e influência social \\
\hline 5 & Inteligência Emocional \\
\hline 6 & Pensamento crítico e analítico \\
\hline 7 & Resolução de problemas complexos \\
\hline 8 & Resiliência, Tolerância ao Stress e flexibilidade \\
\hline 9 & Design tecnológico e programação \\
\hline 10 & Orientação à serviços \\
\hline 11 & Raciocínio, resolução de problemas e ideação \\
\hline 12 & Experiência do usuário \\
\hline 13 & Uso de tecnologias, monitoramento e controle \\
\hline 14 & Análise e avaliação de sistemas \\
\hline 15 & Persuasão e negociação \\
\hline Foñana
\end{tabular}

Fonte: WEF, 2020

\subsection{Diretrizes Curriculares Nacionais do Curso de Graduação em Engenharia}

A Resolução № 2, de 24 de Abril de 2019, instituiu as Diretrizes Curriculares Nacionais do curso de graduação em Engenharia. A resolução estabelece o perfil esperado dos engenheiros; entre outras, o egresso deve possuir as seguintes características (BRASIL, 2019):

I - ter visão holística e humanista, ser crítico, reflexivo, criativo, cooperativo e ético e com forte formação técnica;

II - estar apto a pesquisar, desenvolver, adaptar e utilizar novas tecnologias, com atuação inovadora e empreendedora;

III - ser capaz de reconhecer as necessidades dos usuários, formular, analisar e resolver, de forma criativa, os problemas de Engenharia;

IV - adotar perspectivas multidisciplinares e transdisciplinares em sua prática;

V - considerar os aspectos globais, políticos, econômicos, sociais, ambientais, culturais e de segurança e saúde no trabalho;

$\mathrm{VI}$ - atuar com isenção e comprometimento com a responsabilidade social e com o desenvolvimento sustentável

(BRASIL, 2019, p. 1-2)

As Diretrizes Curriculares Nacionais para o curso de Engenharia ainda definem que os egressos devem desenvolver sensibilidade global, buscar soluções inovadoras para os 
problemas, lidar com situações complexas, comunicar-se eficazmente, trabalhar com e liderar equipes multidisciplinares. Também apresentam que o profissional deve conviver com diferenças socioculturais, atuar com ética e ser capaz de realizar avaliação críticoreflexiva dos impactos das soluções utilizadas (BRASIL, 2019).

\subsection{Desafios da formação profissional em engenharia}

O mundo do trabalho tem passado por grandes alterações provocando desafios para a formação profissional em diversas áreas, inclusive na engenharia. Percebe-se também que uma motivação hegemônica para a entrada em um curso superior é a busca de melhores oportunidades no mundo do trabalho (GROPPO, 2016).

Em sentido convergente com o relatório "O Futuro do Trabalho do Fórum Econômico Mundial, Silva e Cunha (2002) apresentam que a globalização e a sociedade da informação demandam certas características ao trabalhador, a saber: ser criativo, se adaptar facilmente à novos cenários e ter pensamento crítico. Desta forma apenas o título, e por consequência o conhecimento técnico da área não basta para assegurar o trabalho. É preciso que se desenvolvam outras habilidades e capacidades em áreas como comunicação, liderança, relacionamentos interpessoais e conhecimentos interdisciplinares.

De acordo com Laudares et al. (2009) a formação profissional do engenheiro possui quatro grandes desafios: Mudar a percepção sobre o curso de engenharia, flexibilizar os cursos de engenharia, adquirir um currículo tecnológico interdisciplinar e definição da linha pedagógica do curso.

Em 26 de março de 2021 o Conselho Nacional de Educação apresentou a Resolução 1. Ela altera uma parte das Diretrizes Curriculares Nacionais dos cursos de graduação em Engenharia, Arquitetura e Urbanismo e acrescenta na grade curricular obrigatória a disciplina de Desenho Universal. (BRASIL, 2021). É um reflexo da necessidade da formação de profissionais que considerem a diversidade em suas atividades, promovendo inclusão nos projetos, produtos, serviços e ambientes desenvolvidos.

Segundo Toasi et al. (2020) a educação tutorial promove uma aprendizagem compartilhada, potencializa a educação interprofissional e desenvolve habilidades de comunicação e colaboração. A educação também possui papel fundamental para a promoção da democracia e cidadania sendo preciso uma formação ética e conhecimentos da vida social e política (BENEVIDES, 1996). Assim, a vivência em situações fora de sala de aula é um instrumento de formação, ensino e aprendizagem. Pode ser aplicada a qualquer área do conhecimento além de propiciar variadas formas de construção do saber e aliar o conhecimento teórico ao prático. (MAIA et al, 2017).

As DCNs estabelecem em seu oitavo parágrafo que devem ser estimuladas atividades acadêmicas como projetos interdisciplinares e transdisciplinares, voluntariado e participação em empresas juniores. Assim, a formação profissional não se restringe apenas à formação técnica (hard skills) obtida em contextos formais de educação. A formação profissional e pessoal acontece em vários ambientes dentro e fora da sala de aula, devendo o estudante ser estimulado a participar das atividades extracurriculares para melhorar as habilidades técnicas e desenvolver habilidades não técnicas (soft skills).

\subsection{Movimento Estudantil - Características e contribuições}

Nas Instituições de Ensino Superior estão presentes diversas organizações estudantis, com diferentes objetivos, métodos organizacionais e lócus de atuação. Conforme Machado (2008) o Movimento Estudantil promove o debate de reforma universitária, com competência para analisar questões educativas, conseguindo articular e fazer propostas para a universidade e a educação. Ainda assim, algumas ações estudantis 
carecem de incentivo das instituições de ensino, o que dificultam a sua concretização (MAIA et al., 2017).

A taxa de desistência acumulada para os cursos de graduação no país é de $59 \%$, em 2019 e para as engenharias é ainda maior (INEP, 2019). Desta forma, um desafio para as instituições de ensino superior é reduzir a evasão e aumentar a permanência de estudantes nos cursos ofertados. Segundo Groppo e Borges (2018), a participação em organizações estudantis, como grupos religiosos, é um recurso altamente eficaz para garantir a permanência de estudantes na instituição.

Groppo (2016) identifica quatro grandes grupos de organizações juvenis nas instituições de ensino superior: Política institucional, Lazer e Esporte, Religião e Cultura. Além destes, existem outras organizações e vivências estudantis relevantes. O Quadro 02 apresenta os quatro grupos identificados por Groppo (2016) e outros cinco agrupamentos identificados pelos autores deste texto. Ressalta-se que o Quadro 02 não busca exaurir todas as possibilidades de organizações estudantis dentro das instituições de ensino.

Quadro 02: Organizações do Movimento Estudantil

\begin{tabular}{|c|c|}
\hline Agrupamento & Exemplos \\
\hline Lazer, esporte e festas & $\begin{array}{c}\text { Atléticas de Curso, grupos de } \\
\text { camping etc }\end{array}$ \\
\hline Religiosos & $\begin{array}{c}\text { Católicos carismáticos, Meditação } \\
\text { budista, evangélicos etc }\end{array}$ \\
\hline Política Institucional & CA, DA, DCE, UNE etc \\
\hline Manifestaços Culturais & Maracatu, danças regionais etc \\
\hline Formação profissional & $\begin{array}{c}\text { Empresa Jr, Engenheiros Sem } \\
\text { Fronteiras, Crea Jr etc }\end{array}$ \\
\hline Ambientalista & $\begin{array}{c}\text { Agroecologia, Consumo } \\
\text { Sustentável, Reciclagem etc }\end{array}$ \\
\hline Identitários & Mulheres, Negros e Negras, \\
& LGBTI+, PcD etc \\
\hline Ensino, Pesquisa e Extensão & $\begin{array}{c}\text { PET, Baja, Aerodesign, Estágio } \\
\text { Interdiciplinar de Vivência, Ligas } \\
\text { Acadêmicas etc }\end{array}$ \\
\hline Generalistas & $\begin{array}{c}\text { Agrupamentos estudantis com } \\
\text { pautas generalistas, comumente } \\
\text { com atuação nacional ou estadual }\end{array}$ \\
\hline
\end{tabular}

As possibilidades de grupos e entidades são tão variadas quanto a diversidade existente nas juventudes. Também ocorre a participação estudantil como representante em diversos órgãos colegiados das instituições de ensino e em conselhos representativos da sociedade civil.

São vivências e experiências, diferentes e complementares, para as diversas juventudes estudantes. É comum também que alguns estudantes participem simultaneamente de alguns grupos e organizações. Se, por um lado, o excesso de atividades pode provocar desgastes e sobrecarga, por outro lado a participação fortalece a formação pessoal e profissional. O estudante desenvolve habilidades multidisciplinares, de gerenciamento do tempo, resolução de conflitos, criatividade, ética, visão holística, entre outras.

Referindo-se ao Movimento Estudantil da Escola de Engenharia da Universidade Federal de Pernambuco no período de 1958-1975, Machado (2008) avalia: 
A formação profissional não era considerada apenas nos seus aspectos técnicos, mas também do ponto de vista da formação política e da sensibilização para as questões sociais. Os estudantes buscaram monopolizar conhecimentos e práticas na relação mantida com a profissão, bem como procuravam defender que esse conhecimento fosse identificado com as necessidades sociais (MACHADO, 2008, p. 83).

Assim, a participação no Movimento Estudantil contribui para a formação crítica e reflexiva, devendo-se identificar-se com aspectos sociais. São características esperadas nos egressos dos cursos, de acordo com as DCNs e o relatório "O Futuro do Trabalho". O trecho destacado corrobora a hipótese avaliada no estudo. Percebe-se a importância do Movimento Estudantil para o desenvolvimento das soft skills dos estudantes de engenharia, em complemento com as hard skills.

\section{DISCUSSÃO DOS RESULTADOS}

Uma característica muito marcante do Movimento Estudantil é a transitoriedade, que é provocada pela perspectiva de término da condição de estudante, seja por formatura ou desligamento. Outro fator que contribui para a transitoriedade é a duração da gestão de entidades e organizações estudantis comumente ser de um ano.

O acúmulo de conhecimento dentro do Movimento Estudantil é constantemente defasado, devido à transitoriedade existente. A transitoriedade é um fluxo constante de entrada e saída de membros das organizações estudantis. Alguns pontos que provocam a essa constante transição são a formatura no curso, a troca de gestão ou o afastamento pessoal. A transitoriedade provoca uma dinâmica rápida e intensa para o Movimento Estudantil, potencializando o desenvolvimento das competências identificadas.

A transitoriedade existente no Movimento Estudantil provoca alguns efeitos desejáveis na ótica da formação profissional. Pelo curto período de participação, as atividades são intensas, exigindo um rápido crescimento pessoal de seus membros. São desenvolvidas habilidades como inciativa, criatividade, liderança, resiliência, comunicação, capacidade de lidar com problemas complexos entre outras. Os integrantes das entidades, organizações estudantis e representantes discentes também lidam com profissionais que tem experiência consolidada em sua área de atuação como reitores, pró-reitores, políticos, professores, empresas e profissionais. Desta forma são desenvolvidas habilidade como persuasão e negociação, capacidade analítica, liderança, resistência ao stress entre outras.

Para compreender melhor a interface existente, são apresentadas algumas situações vivenciadas por estudantes ao participarem do Movimento Estudantil. A primeira é referente à organização de eventos locais como por exemplo Semanas Acadêmicas. Em várias universidades as entidades estudantis realizam eventos locais, as vezes organizando junto com outros organizações e a própria instituição de ensino. Várias habilidades são desenvolvidas ao se realizar a organização local de eventos. Considerando habilidades técnicas, os estudantes devem conseguir fazer a gestão do tempo, de recursos e de projetos de forma adequada para se alcançar o objetivo planejado. Outras habilidades não técnicas também são desenvolvidas como iniciativa, comunicação e criatividade e originalidade.

Ainda que algumas organizações adotem um modelo horizontal de gestão, outras várias possuem um modelo verticalizado ou seja, com cargos definidos. É definido quem estará na presidência, secretaria, tesouraria e outras diretorias, sendo um processo que empodera os participantes ao Ihes atribuir responsabilidades formais. Para que consigam exercer suas funções, Ihes serão exigidas capacidades como liderança, negociação, 
persuasão, resiliência, pensamento analítico, criatividade entre outras. Passa-se por um processo de autodesenvolvimento de diversas soft skills. Também são desenvolvidas hard skills pertinentes à função exercida. Ressalta-se que processo similar de desenvolvimento é percebido em organizações com maior horizontalidade em seu processo de direção.

Nas universidades existem diversos conselhos e câmaras colegiados para definição ou consulta de determinados assuntos acadêmicos, administrativos, culturais entre outros. A composição dos conselhos é altamente heterogênea dentro e entre as instituições, mas em vários conselhos se tem uma representação estudantil. Em alguns momentos a representação estudantil apresenta pautas que são inicialmente contrárias ao que é defendido pela administração da instituição exigindo da representação boa capacidade de influência social, comunicação e resiliência para conseguir apresentar e aprovar as pautas próprias, em conselhos cuja categoria é minoritariamente representada. Em situações de convergência também são desenvolvidas habilidades como capacidade de análise crítica e visão holística.

Complementando, o/a representante discente deve conseguir se expressar oralmente e por escrito com a devida formalidade existente nos espaços e também deve conseguir transmitir em um curto tempo suas ideias e proposições. A representação estudantil desenvolve outras soft skills como por exemplo alta capacidade de negociação e persuasão, resiliência, tolerância ao estresse, comunicação, pensamento rápido e analítico. A participação em conselhos e câmaras das instituições é um caminho para a construção efetiva da universidade com a formulação de propostas e compreensão de processos acadêmicos e administrativos existentes. Além das contribuições para a comunidade acadêmica, a participação nestas instâncias propicia um desenvolvimento pessoal, profissional e cidadão aos seus membros, fortalecendo a formação profissional e a formação para a cidadania.

Uma outra situação recorrente é a participação de estudantes em grupos e entidades nacionais ou estaduais do Movimento Estudantil. Alguns exemplos são a União Nacional dos Estudantes (UNE), entidade representativa dos estudantes brasileiros de graduação, a Associação Nacional de Pós Graduandos e Pós Graduandas (ANPG), entidade que representa os estudantes de pós graduação do país e os diversos coletivos estudantis e de juventude existentes, como o Coletivo Quilombo (Coletivo de juventude, direitos humanos e educação, com atuação nacional). Nesse ponto também é considerada a participação em conselhos da sociedade civil como o CONJUVE - Conselho Nacional da Juventude e o CNS - Conselho Nacional de Saúde. Novamente, além de contribuir para o desenvolvimento da cidadania, a participação nestes espaços contribui para a formação profissional. Ao participar da direção/composição destas organizações é perceptível o desenvolvimento de diversas habilidades e competências devido à necessidade de lidar com problemas complexos. Algumas são liderança, gestão, comunicação, capacidade de análise, visão holística e comportamento em situações críticas e de estresse. Assim como nas outras situações, também ocorre o desenvolvimento de habilidades técnicas mais simples como escrita e compreensão de ofícios e documentos formais até as mais complexas como a gestão de projetos que envolvem custos milionários de âmbito nacional. Considerando os quatro aspectos apresentados por Laudares et al. (2009) para a formação profissional, avalia-se que a participação em movimentos estudantis contribui para os quatro desafios pois flexibiliza a formação profissional promovendo a interdisciplinaridade, fortalece a permanência e percepção do curso além de contribuir para o projeto pedagógico.

$\mathrm{O}$ aumento da interdisciplinaridade e o fomento à participação em organizações estudantis possibilita ao estudante e futuro profissional de engenharia uma melhor inserção nos grupos de trabalho multidisciplinares em que vier constituir, além de ter uma formação mais ampla, condizente com necessidades organizacionais e com as rápidas mudanças 
tecnológicas e sociais. Considerando as quinze habilidade de maior demanda nas organizações e as características e situações apresentadas, o Movimento Estudantil consegue potencializar diretamente nove delas, além de contribuir indiretamente para as outras. As habilidades que apresentam alta demanda nas organizações e que são diretamente desenvolvidas ao se participar no Movimento Estudantil e organizações juvenis são: 2. Pensamento analítico e inovação, 3. Criatividade, Originalidade e Iniciativa, 4. Liderança e influência social, 5. Inteligência Emocional, 6. Pensamento Crítico e analítico, 7. Resolução de problemas complexos, 8. Resiliência, Tolerância ao Stress e Flexibilidade, 11. Raciocínio, resolução de problemas e ideação e 15. Persuasão e Negociação.

As DCNs para os cursos de engenharia definem seis características desejadas no egresso de engenharia, conforme visto anteriormente. Avalia-se que todas as características desejáveis são diretamente desenvolvidas pela participação no Movimento Estudantil. Inclusive, os espaços formais de educação podem ter dificuldade em desenvolver algumas dessas soft skills, seja pelo tempo disponível para as disciplinas, seja pelo foco no desenvolvimento de hard skills.

Pelos pontos e situações abordados, avalia-se que são diretamente desenvolvidas as características e competências: "I - ter visão holística e humanista, ser crítico, reflexivo, criativo, cooperativo e ético (...)"; "III - ser capaz de reconhecer as necessidades dos usuários, formular, analisar e resolver, de forma criativa, os problemas de Engenharia"; "IV - adotar perspectivas multidisciplinares e transdisciplinares em sua prática"; " $V$ - considerar os aspectos globais, políticos, econômicos, sociais, ambientais, culturais e de segurança e saúde no trabalho" e "VI - atuar com isenção e comprometimento com a responsabilidade social e com o desenvolvimento sustentável".

A segunda característica necessita de uma maior discussão para o entendimento. Ela define que o egresso deve "II - estar apto a pesquisar, desenvolver, adaptar e utilizar novas tecnologias, com atuação inovadora e empreendedora". O Movimento Estudantil promove as capacidades de adaptação e inovação, que serão poderão ser utilizadas para as novas tecnologias. Porém, ao se considerar a participação em grupos estudantis como Empresa Júnior ou PET, essa habilidade passa a ser diretamente desenvolvida, juntamente com as demais.

Compreendendo a contribuição que o Movimento Estudantil propicia para a formação profissional, é importante compreender como fomentar a participação estudantil institucionalmente. É no projeto pedagógico do curso (PPC) que são definidos quais conteúdos e competências o curso desenvolverá além da forma como será realizado (BRASIL, 2019). No Art. 6ㅜㅡ, alínea IV da Resolução 2 de das DCNs, se estabelece que os projetos pedagógicos dos cursos de engenharia devem contemplar "as atividades complementares que se alinhem ao perfil do egresso e às competências estabelecidas". e no Art. $10^{\circ}$ que estas devem contribuir para o desenvolvimento dos egressos.

Avalia-se que a participação nas organizações e movimentos estudantis alcançam o objetivo definido no Art. 10 por três meios. Primeiramente, são atividades complementares que contribuem efetivamente para o desenvolvimento e formação profissional de estudantes e egressos dos cursos de engenharia. Em segundo, auxiliam a reduzir a alta evasão escolar e por último potencializam a formação cidadã necessária à educação. Em vista disso é primordial avaliar como fomentar e potencializar a participação de estudantes nas variadas organizações e movimentos estudantis existentes, sendo o Projeto Pedagógico um possível meio para tal.

Como documento regente do curso, o Projeto Pedagógico deve ser fruto de constante reflexão e atualização. Dessarte, sugere-se que a reflexão, inclusão, valorização e fomento das atividades de grupos, organizações e movimentos estudantis e juvenis no Projeto Pedagógico dos Cursos de Engenharia. O Projeto Pedagógico do curso é o 
documento norteador das atividades pedagógicas e a inclusão dos pontos abordados reflete na institucionalização do incentivo à participação e consequente formação profissional. Importante ressaltar que o projeto pedagógico deve ser verificado frequentemente para garantir a efetivação das orientações definidas e garantir as atualizações necessárias.

O Movimento Estudantil contribui em dois momentos para a elaboração do Projeto Pedagógico do curso. O primeiro momento ao ser um possível caminho para a formação interdisciplinar, humanizada, cidadã, diversa e crítica dos profissionais de engenharia. A segunda é demandando as mudanças nos cursos e instituições, de forma a melhorar a formação à qual os estudantes estão submetidos. O segundo ponto ocorre principalmente por meio das representações estudantis em Centros e Diretórios Acadêmicos e também como representantes discentes nos órgãos universitários, sejam de gestão acadêmica ou administrativa.

Nota-se que existem diferentes trilhas que contribuem para a formação profissional, além da sala de aula e dos laboratórios de pesquisa. Estas trilhas se caracterizam por propiciarem ao estudante a vivência de outras realidades, contribuindo para sua formação profissional, ampla e cidadã. Se revelam essenciais para uma formação plena do egresso de engenharia, tal que possa contribuir para o desenvolvimento de soluções para as organizações ao considerar aspectos além do puramente técnico.

Considerando os fatores apresentados, confirma-se a hipótese apresentada "A participação no Movimento Estudantil contribui para a formação profissional em engenharia". Foram utilizados os pontos apresentados pelo Fórum Econômico Mundial e pelas Diretrizes Curriculares Nacionais para os cursos de Engenharia. A participação propicia o desenvolvimento de soft skills que os espaços formais podem ter dificuldade em aprimorar, complementando as habilidades técnicas construídas e também potencializa o desenvolvimento de hard skills.

O Movimento Estudantil é diverso e apresenta uma variedade de possibilidades e frentes de atuação. Não apenas é possível, como é desejável que o estudante participe de alguma organização estudantil. A participação no Movimento Estudantil contribui efetivamente para o desenvolvimento pessoal, profissional e cidadão do estudante, devendo ser incentivado.

\section{CONSIDERAÇÕES FINAIS}

As habilidades e competências demandadas dos profissionais tem se alterado ao longo dos últimos anos e a pandemia de COVID19 acelerou esse processo. O relatório "O Futuro do Trabalho" do Fórum Econômico Mundial e as DCNs para engenharia são fontes importantes de informação para se entender quais são as habilidades e competências à serem desenvolvidas nos estudantes e futuros profissionais de engenharia.

As instituições de ensino exercem papel fundamental na formação profissional ao realizar atividades de ensino, pesquisa e extensão. A formação profissional, entretanto, não ocorre apenas em espaços educacionais formais, mas também em diversos outros espaços informais além do que espaços formais podem apresentar limitações em desenvolver algumas soft skills mas que são facilmente construídas em outras instâncias de atividades extracurriculares.

Além da participação nas diversas entidades e organizações do Movimento Estudantil, estudantes também podem ser representantes em órgãos colegiados das instituições de ensino e da sociedade. Ao ser representante nestes espaços também é perceptível o desenvolvimento de diversas habilidades. Entendendo as demandas organizacionais e educacionais da formação profissional em engenharia $e$ as 
características do Movimento Estudantil, a hipótese "A participação no Movimento Estudantil contribui para a formação profissional em Engenharia" foi confirmada. Este estudo também contribui para que os participantes de organizações estudantis possam avaliar e perceber ativamente as habilidades que são desenvolvidas.

As instituições de ensino devem fomentar a participação de estudantes nos movimentos estudantis. Seja garantindo o direito de livre organização, seja destinando recursos para a realização das atividades, seja pelo reconhecimento institucional ao se inserir a possibilidade nos projetos pedagógicos. Além da formação social e cidadã e inegável contribuição para a construção das instituições de ensino e sociedade, o Movimento Estudantil desenvolve diversas habilidades profissionais e pessoais desejáveis aos egressos dos cursos de engenharia, potencializando o desenvolvimento de soft skill e hard skills importantes para as organizações.

\section{REFERÊNCIAS}

BENEVIDES, Maria Victoria de Mesquita. Educação para a democracia. Lua Nova: Revista de Cultura e Política, [S.L.], n. 38, p. 223-237, dez. 1996. FapUNIFESP (SciELO). http://dx.doi.org/10.1590/s0102-64451996000200011.

BRASIL. Ministério da Educação. Conselho Nacional de Educação Câmara de Educação Superior. Resolução CNE/CES no 2, de 24 de Abril de 2019. Institui as Diretrizes Curriculares Nacionais do Curso de Graduação em Engenharia. Diário Oficial da União. 24 Abr 2019.

BRASIL. Ministério da Educação. Conselho Nacional de Educação Câmara de Educação Superior. Resolução CNE/CES no 1, de 26 de Março de 2021 Altera o Art. 9º $\S 1^{\circ}$ da Resolução CNE/CES 2/2019 e o Art. 6 ${ }^{\circ}$ § 1ํ da Resolução CNE/CES 2/2010, que institui as Diretrizes Curriculares Nacionais dos Cursos de Graduação de Engenharia, Arquitetura e Urbanismo. Diário Oficial da União. 26 Mar 2021

GROPPO, Luis Antonio. Juventudes universitárias: participação política e processos educativos em uma universidade do interior de minas gerais. Educativa, Goiânia, v. 19, n. 1, p. 838-859, dez. 2016. Http://dx.doi.org/10.18224/educ.v19i3.5440 .

GROPPO, Luís Antonio; BORGES, Lívia Furtado. Grupo evangélico na universidade: práticas formativas, identidade religiosa e relações políticas. Religião \& Sociedade, Rio de Janeiro, v. 38, n. 3, p. 173-196, dez. 2018. FapUNIFESP (SciELO). http://dx.doi.org/10.1590/0100-85872018v38n3cap08

Instituto Nacional de Estudos e Pesquisas Educacionais Anísio Teixeira - INEP. 2019. Microdados do Censo da Educação Superior 2019. https://www.gov.br/inep/ . Acesso em: 27 de mar. 2021.

LAUDARES, João Bosco et al. O ensino de engenharia e a formação do engenheiro: contribuição do programa de mestrado em tecnologia do CEFET-MG - educação tecnológica. Educação \& Tecnologia, Belo Horizonte, v. 14, n. 1, p. 60-67, abr. 2009.

MACHADO, Otávio L. Formação profissional, ensino superior e a construção da profissão de engenheiro pelos movimentos estudantis de engenharia: A experiência a partir da escola de engenharia da Universidade Federal de Pernambuco (1958-1975). 
Dissertação (Mestrado) - Curso de Sociologia. Universidade Federal de Pernambuco, Recife, 2008.

MAIA, Estela da Silva et al. Estágios de vivência: ferramenta de ensino e aprendizagem. Elo: Diálogos em Extensão, Viçosa, v. 6, n. 3, p. 51-55, dez. 2017.

TOASSI, Ramona Fernanda Ceriotti et al. Ensino da graduação em cenários da atenção primária: espaço para aprendizagem interprofissional. Trabalho, Educação e Saúde, [S.L.], v. 18, n. 2, p. 1-18, 2020. FapUNIFESP (SciELO). http://dx.doi.org/10.1590/1981$\underline{7746-s o l 00267}$

World Economic Forum - WEF. The Future of Jobs Report: 2020. [S. L.]: WEF, 2020. 163 p. Disponível em: https://www.weforum.org/reports/the-future-of-jobs-report-2020. Acesso em: 05 abr. 2021.

\title{
ENGINEERING AND STUDENT ACTIVISM: INTERFACES OF PROFESSIONAL TRAINING
}

\begin{abstract}
The Student Activism plays an important role in the debates on education in the country, being the path taken by students in the organization and presentation of demands and proposals to improve of education. Several studies reveal that participation in the student activism contributes to social and citizen education but it is necessary to understand how the interface between this participation and professional education occurs. The aim of this study is to understand this interface and deepen the knowledge about participation in complementary activities and professional training. This study is based on the hypothesis "Participation in the student movement contributes to professional training in engineering". A literature review was carried out to understand the relevant points for professional training in engineering, which challenges exist and the student organization's characteristics. Then an analysis and discussion of the data was carried out in which the initial hypothesis was confirmed, since participation in the student movement develops several soft skills and hard skills that are expected in educational training and desirable in professional performance.
\end{abstract}

Keywords: Professional Training, Student Activism, Engineering Education, Skills 